\title{
A mosquito predator survey in Townsville, Australia, and an assessment of Diplonychus sp. and Anisops sp. predatorial capacity against Culex annulirostris mosquito immatures
}

\author{
Essam Abdel-Salam Shaalan ${ }^{1}$, Deon Vahid Canyon ${ }^{2 凶}$, Reinhold Muller ${ }^{2}$, \\ Mohamed Wagdy Faried Younes ${ }^{3}$, Hoda Abdel-Wahab ${ }^{1}$, and Abdel-Hamid Mansour ${ }^{1}$ \\ ${ }^{1}$ Zoology Department, Aswan Faculty of Science, South Valley University, Aswan, Egypt \\ ${ }^{2}$ School of Public Health, Tropical Medicine \& Rehabilitation Science, James Cook University, Townsville, Qld 4811, Australia \\ ${ }^{3}$ Zoology Department, Faculty of Science, Menoufia University, Shebin El-Kom, Egypt
}

Received 6 April 2006; Accepted 28 December 2006

\begin{abstract}
A twelve-month survey for mosquito predators was conducted in Townsville, Queensland, Australia, which is located in the arid tropics. The survey revealed the presence of five predaceous insects but only Anisops sp. (backswimmers) and Diplonychus sp. were common. Predatorial capacity and factors influencing this capacity were then assessed for adult Anisops sp. and adult and nymph stages of Diplonychus sp. against Culex annulirostris mosquito immatures under laboratory conditions. Predatorial capacity bioassays showed that adult Diplonychus sp. preyed upon both larval and pupal stages of Cx. annulirostris quite successfully. Nymphs of Diplonychus sp. proved to be more successful with smaller prey immatures, and Anisops sp adults did not prey successfully on any prey pupae. Increasing the foraging area and introducing aquatic vegetation significantly reduced the predatorial capacity of Diplonychus sp. nymphs, while only vegetation and not foraging area had a significant effect on adult Diplonychus sp. predation capacity. Overall, adult Diplonychus sp. proved to be a more efficient predator than Anisops sp., and field trials are now recommended to further assess the potential of Diplonychus sp. as a biocontrol agent. Journal of Vector Ecology 32 (1): 16-21. 2007.
\end{abstract}

Keyword Index: Biological control, predator, mosquito, Hemiptera.

\section{INTRODUCTION}

A variety of aquatic insects in the orders Odonata, Hemiptera, Coleoptera, and Diptera are known to prey upon mosquito larvae. Generalist predators that feed on a broad range of prey species are polyphagous, while specialist predators with a restricted range of prey can be oligophagous or monophagous with a limited range or single species of prey. Although most predators of mosquitoes tend to be generalists (Collins and Washino 1985), there are exceptions. For instance, Washino (1969) found that corixids fed less upon mosquito larvae than any other hemipteran predators (Corisella sp., Belostoma flumineum, and the giant waterbug Abedus indentatus) when tested experimentally. On the other hand, Notonecta undulata was found to prefer mosquito larvae over other prey like corixids, ephemedrids, chironomids, and chaoborids when given a choice (Ellis and Borden 1970), indicating a degree of predatory specialization.

Although predation may occur during any prey life stage, research has focused on the immature larval and pupal stages. Egg predation appears to be a minor component of mosquito mortality and predation on the adult stage is unlikely to provide reliable levels of control (Collins and Washino 1985). Few predators, particularly Toxorhynchites larvae, kill mosquito pupae without ingesting them afterwards. This killing activity is fortunate in the context of control, because pupal production is most highly correlated with subsequent adult densities (Padgett and Focks 1981).

Laboratory research into aquatic insect predation is fairly common and studies of aquatic bugs have shown that they are quite effective predators of mosquito larvae. For instance, Miura and Takahashi (1988) demonstrated that Microvelia pulchella (Hemiptera: Vellidae) is able to derive nutrients from mosquito larvae to survive, grow, and reproduce. Venkatesan and Sivaraman (1984) investigated the predation potential of the water bug Diplonychus indicus (Hemiptera: Belostomatidae) against larval instars of two different mosquito prey species, Aedes aegypti and $C x$. fatigans, at varying densities. They showed that the largest predator $\left(5^{\text {th }}\right.$ instar) was more effective than smaller instars at killing the smallest prey ( $1^{\text {st }}$ instar). This was due to larger predator instars exhibiting more successful attacks and a shorter handling time than smaller predator instars. Similarly, Scott and Murdoch (1983) found that when the backswimmer Notonecta huffmani was fed on mosquito larvae under laboratory conditions, its appetite decreased with increasing prey size. The same behavior was observed in the notonectid bug Enithares indica (Wattal et al. 1996). The feeding rates of $E$. indica on the immature stages of Anopheles stephensi and Cx. quinquefasciatus decreased with increasing mosquito larval stage. Maximum predation was observed on $1^{\text {st }}$ instar larvae while minimum predation was observed for the pupal stage. 
The aforementioned studies investigated the predation potential of some hemipteran predators and their prey preference against immature stages of different mosquito species. Hence the present work, located in Townsville, North Queensland, Australia, advanced this research by investigating the predatorial capacity of Anisops sp. and Diplonychus sp. using Cx. annulirostris (Skuse) as prey. We addressed how two factors, the size of foraging area and the presence of vegetation, might affect predatorial capacity.

\section{MATERIALS AND METHODS}

\section{Field survey}

Local predators were surveyed and collected to identify the most prevalent species and to subsequently investigate their efficacy against mosquito immatures. Being located in the arid tropics, almost no suitable breeding sites were found that contained water throughout the year, so nearpermanent flood areas were selected. A fresh water runoff marsh with occasional brackish water was selected in Oonoonba (a peri-urban suburb adjacent to extensive mangrove habitat) and a receding marshy brackish lake often frequented by wild pigs and crocodiles was selected in the city's Town Common (a conservation park). These sites were surveyed monthly using long-handled nets with $15 \mathrm{~cm}$ diameter x $30 \mathrm{~cm}$ long muslin sleeves. Predators were transported alive from the field to the laboratory in plastic boxes half-filled with water and debris from the breeding sites. In the laboratory, predators were washed with clean water and sorted into small plastic trays $(15 \times 11 \times 5 \mathrm{~cm})$ half-filled with de-ionized water. They were identified according to keys of Gooderham and Tsyrlin (2002) and left to acclimatize to laboratory conditions. All predators were starved for two days before tests were conducted.

\section{Experiment 1}

The predatorial efficacy assessment of adult Anisops sp. and Diplonychus sp. on Cx. annulirostris immature prey was conducted in glass beakers $(500 \mathrm{ml})$ using five different life stages of the prey $\left(1^{\text {st }}, 2^{\text {nd }}, 3^{\text {rd }}\right.$, or $4^{\text {th }}$ larval instars or pupae) and in $250 \mathrm{ml}$ of de-ionized water. All settings were controlled and replicated four times. Each experimental beaker contained 25 immature mosquitoes of the same life stage and one predator. Identical settings were used as controls but contained no predators. The outcome was assessed after $24 \mathrm{~h}$ by counting the number of immatures consumed or killed by the predators. Killed immature stages were distinguished by lack of movement, darker coloring and distorted shape. Since the initial tests showed that adult Anisops sp. were less effective, additional experiments were conducted using Diplonychus sp. nymphs.

\section{Experiment 2}

The effect of foraging area size and the presence of vegetation was assessed by replicating the above described settings (Experiment 1) twice in larger plastic containers $(15 \times 11 \times 5 \mathrm{~cm}$ with $700 \mathrm{ml}$ of de-ionized water) with and without the addition of seven branches of aquatic weed of the same length, which were collected from the breeding sites. Anisops sp. were dropped from these series of experiments since the inability of Anisops sp. to predate on pupae (Experiment 1) is a predatorial flaw that renders the species ineffective as a mosquito predator.

All data analysis was performed using factorial ANOVA models (SPSS ver. 12.0.1 for Windows).

\section{RESULTS}

\section{Field survey}

Five different species of predators (Table 1) representing two Orders (Hemiptera and Odonata), were collected from the two survey sites over a 12-month period. All predators were found in the Oonoonba site, but only two of them were collected from the Town Common. The hemipteran

Table 1. Survey of aquatic predaceous insects in the peri-urban suburb of Oonoonba and the Town Common conservation park in Townsville Qld Australia (+ predators were present; - predators were absent).

\begin{tabular}{|c|c|c|c|c|c|c|c|}
\hline \multirow{2}{*}{ Date } & \multicolumn{5}{|c|}{ Oonoonba } & \multicolumn{2}{|c|}{$\begin{array}{l}\text { Town Common } \\
\text { Order Hemiptera }\end{array}$} \\
\hline & $\begin{array}{l}\text { Anisops } \\
\text { sp. }\end{array}$ & Diplonychussp. & Corixids & Damselflies & Dragonflies & $\begin{array}{l}\text { Anisops } \\
\text { sp. }\end{array}$ & $\begin{array}{c}\text { Diplonychus } \\
\text { sp. }\end{array}$ \\
\hline $04 / 03$ & + & + & - & + & + & + & + \\
\hline $05 / 03$ & + & + & - & + & + & + & + \\
\hline $06 / 03$ & - & - & - & - & - & - & + \\
\hline 07/03 & - & - & - & - & - & - & - \\
\hline 08/03 & - & - & - & - & - & - & - \\
\hline $09 / 03$ & + & - & + & - & - & - & - \\
\hline $10 / 03$ & - & - & - & - & - & - & - \\
\hline $11 / 03$ & - & - & - & - & - & - & - \\
\hline $12 / 03$ & - & - & - & - & - & - & - \\
\hline $01 / 04$ & - & + & - & - & + & - & - \\
\hline $02 / 04$ & - & + & - & - & - & + & + \\
\hline 03/04 & - & + & - & + & + & - & + \\
\hline
\end{tabular}


Table 2. Factorial one-way ANOVA models for Anisops sp. adults, Diplonychus sp. adults and Diplonychus sp. nymphs and a summary.

\begin{tabular}{|c|c|c|c|c|c|}
\hline $\begin{array}{l}\text { Anisops sp. adults } \\
\text { Source } \\
\text { Between Groups }\end{array}$ & $\begin{array}{r}\mathrm{DF} \\
4 \\
\end{array}$ & $\begin{array}{r}M S \\
6093.2000\end{array}$ & $\begin{array}{r}\text { F Ratio } \\
42.7893 \\
\end{array}$ & $\begin{array}{l}\text { F Prob } \\
0.0000 \\
\end{array}$ & \\
\hline Group (Prey stage) & Count & Mean & SD & SE & $95 \% \mathrm{CI}$ \\
\hline $1^{\text {st }}$ Instar & 4 & 100.00 & 0.00 & 0.00 & $100.00-100.00$ \\
\hline $2^{\text {nd }}$ Instar & 4 & 87.00 & 15.79 & 7.90 & $61.87-112.13$ \\
\hline $3^{\text {rd }}$ Instar & 4 & 72.00 & 11.31 & 5.66 & $54.00-90.00$ \\
\hline $4^{\text {th }}$ Instar & 4 & 53.00 & 18.29 & 9.15 & $23.89-82.11$ \\
\hline Pupae & 4 & 0.00 & 0.00 & 0.00 & $0.00-0.00$ \\
\hline Total & 20 & 62.40 & 37.35 & 8.35 & $44.92-79.88$ \\
\hline \multicolumn{6}{|l|}{ Diplonychus sp. adults } \\
\hline Source & DF & MS & F Ratio & F Prob & \\
\hline Between Groups & 4 & 11.2500 & 1.000 & 0.4380 & \\
\hline Group (Prey stage) & Count & Mean & $\mathrm{SD}$ & SE & $95 \% \mathrm{CI}$ \\
\hline $1^{\text {st }}$ Instar & 4 & 100.00 & 0.00 & 0.00 & $100.00-100.00$ \\
\hline $2^{\text {nd }}$ Instar & 4 & 100.00 & 0.00 & 0.00 & $100.00-100.00$ \\
\hline $3^{\text {rd }}$ Instar & 4 & 100.00 & 0.00 & 0.00 & $100.00-100.00$ \\
\hline $4^{\text {th }}$ Instar & 4 & 100.00 & 0.00 & 0.00 & $100.00-100.00$ \\
\hline Pupae & 4 & 96.25 & 7.50 & 3.75 & $84.32-108.18$ \\
\hline Total & 20 & 99.25 & 3.35 & 0.75 & $97.68-100.82$ \\
\hline \multicolumn{6}{|l|}{ Diplonychus sp. nymphs } \\
\hline Source & DF & MS & F Ratio & F Prob & \\
\hline Between Groups & 4 & 2519.2000 & 55.2456 & 0.0000 & \\
\hline Group (Prey stage) & Count & Mean & $\mathrm{SD}$ & SE & $95 \% \mathrm{CI}$ \\
\hline $1^{\text {st }}$ Instar & 4 & 100.00 & 0.00 & 0.00 & $100.00-100.00$ \\
\hline $2^{\text {nd }}$ Instar & 4 & 100.00 & 0.00 & 0.00 & $100.00-100.00$ \\
\hline $3^{\text {rd }}$ Instar & 4 & 96.00 & 8.00 & 4.00 & $83.27-108.73$ \\
\hline $4^{\text {th }}$ Instar & 4 & 80.00 & 8.64 & 4.32 & $66.25-93.75$ \\
\hline Pupae & 4 & 41.00 & 9.45 & 4.73 & $25.96-56.04$ \\
\hline Total & 20 & 83.40 & 23.80 & 5.32 & $72.26-94.54$ \\
\hline \multicolumn{6}{|l|}{ Summary } \\
\hline Source & DF & MS & F Ratio & F Prob & \\
\hline Between Groups & 2 & 6833.8167 & 10.3920 & 0.0001 & \\
\hline Group & Count & Mean & $\mathrm{SD}$ & $\mathrm{SE}$ & $95 \% \mathrm{CI}$ \\
\hline Anisops sp. adults & 20 & 62.40 & 37.35 & 8.35 & $77.92-79.88$ \\
\hline Diplonychus sp. adults & 20 & 99.25 & 3.35 & 0.75 & $97.68-100.82$ \\
\hline Diplonychus sp. nymphs & 20 & 83.40 & 23.80 & 5.32 & $72.26-94.54$ \\
\hline Total & 60 & 81.68 & 29.44 & 3.80 & $74.08-89.29$ \\
\hline
\end{tabular}

bugs Anisops sp. (Notonectidae) and Diplonychus sp. (Belostomatidae) were encountered at both sites while damselflies, dragonflies (Odonata), and corixid bugs (Corixidae: Hemiptera) were collected only from Oonoonba. Both Anisops sp. (backswimmers) and Diplonychus sp. were the most common predators followed by damselflies and dragonflies. The five corixid bugs were found in September.

\section{Experiment 1}

Predatorial efficacy in relation to prey life stage differed significantly in Anisops sp. adults and Diplonychus sp. nymphs, but not in Diplonychus sp. adults (Table 2). There was a significant difference between the overall sum eaten between the different types of predators (Tables 2 and 3 ) $(\mathrm{p}<0.001)$.

\section{Experiment 2}

Table 4 details the results for Experiment 2. Increasing the foraging area and including vegetation made it significantly more difficult for predators to catch prey (Figures 1 and 2). Diplonychus sp. adults were significantly better than Diplonychus sp. nymphs at predating on $C x$. annulirostris immatures. There was also a significant overall difference with respect to prey stage in the sense that the more developed the immatures, the fewer were caught. One significant interaction (all possible 2-way and 3-way interactions were assessed) was found between prey stage and predator "age": Diplonychus sp. nymphs, while being quite successful with small prey, experience significantly more difficulty when preying on older prey than do Diplonychus sp. adults that prey on all $C x$. annulirostris immature stages without difficulty. These results seem quite stable since all these factors together explain close to twothirds of the variability in the data.

\section{DISCUSSION}

It is important to correlate predator and prey seasonality and habitats if mosquito control is to be considered for a particular predator that has proven to be effective in experimental conditions. An ecological and biological study by Rae (1990) at the Ross River Dam, North Queensland, Australia, located in the same geographical region as this study, indicated the prevalence of several predacious 


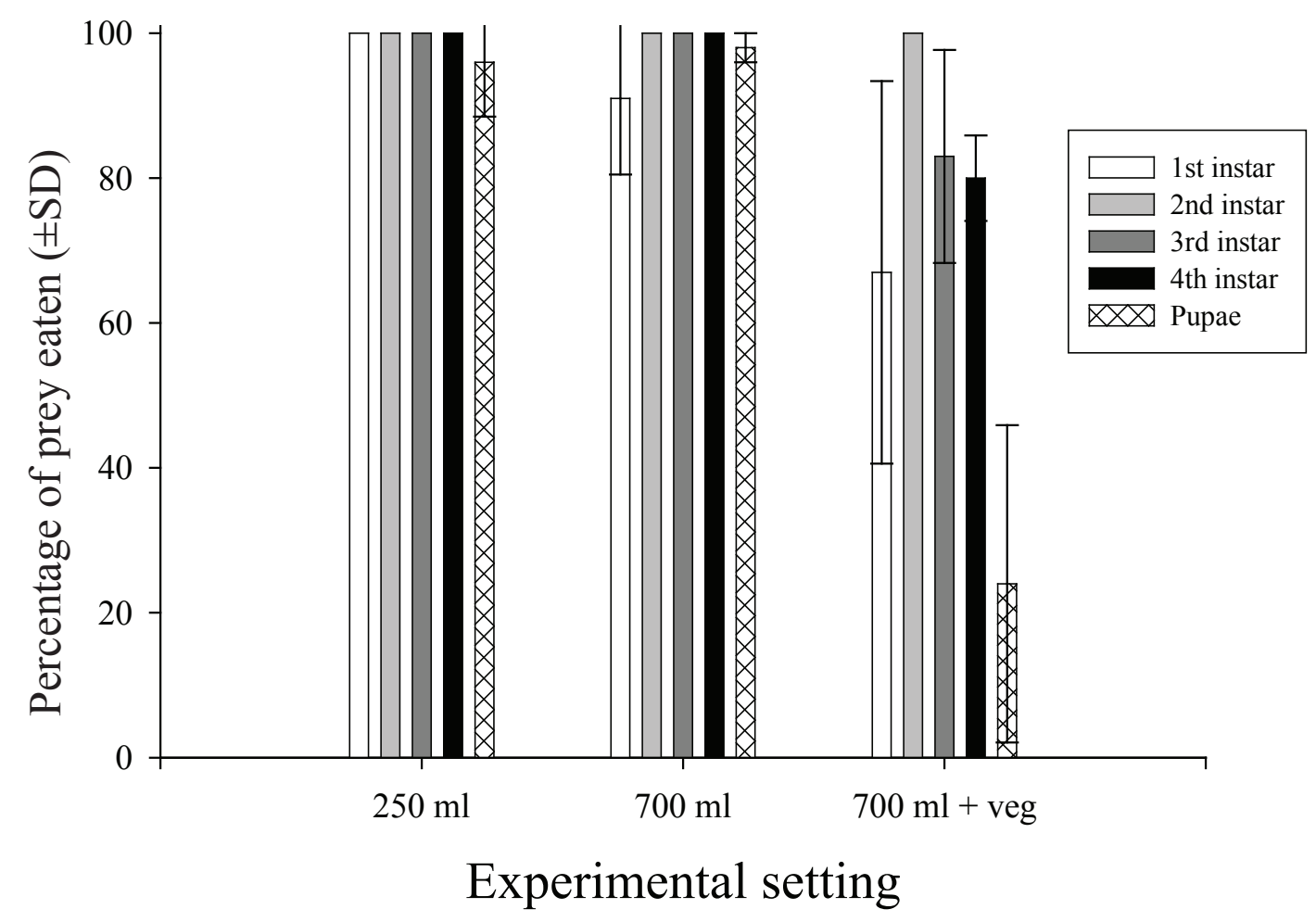

Figure 1. Predatorial capacity of Diplonychus sp. adults against different Culex annulirostris immatures in different settings (250 $\mathrm{ml}, 700 \mathrm{ml}$, and $700 \mathrm{ml}+$ vegetation).

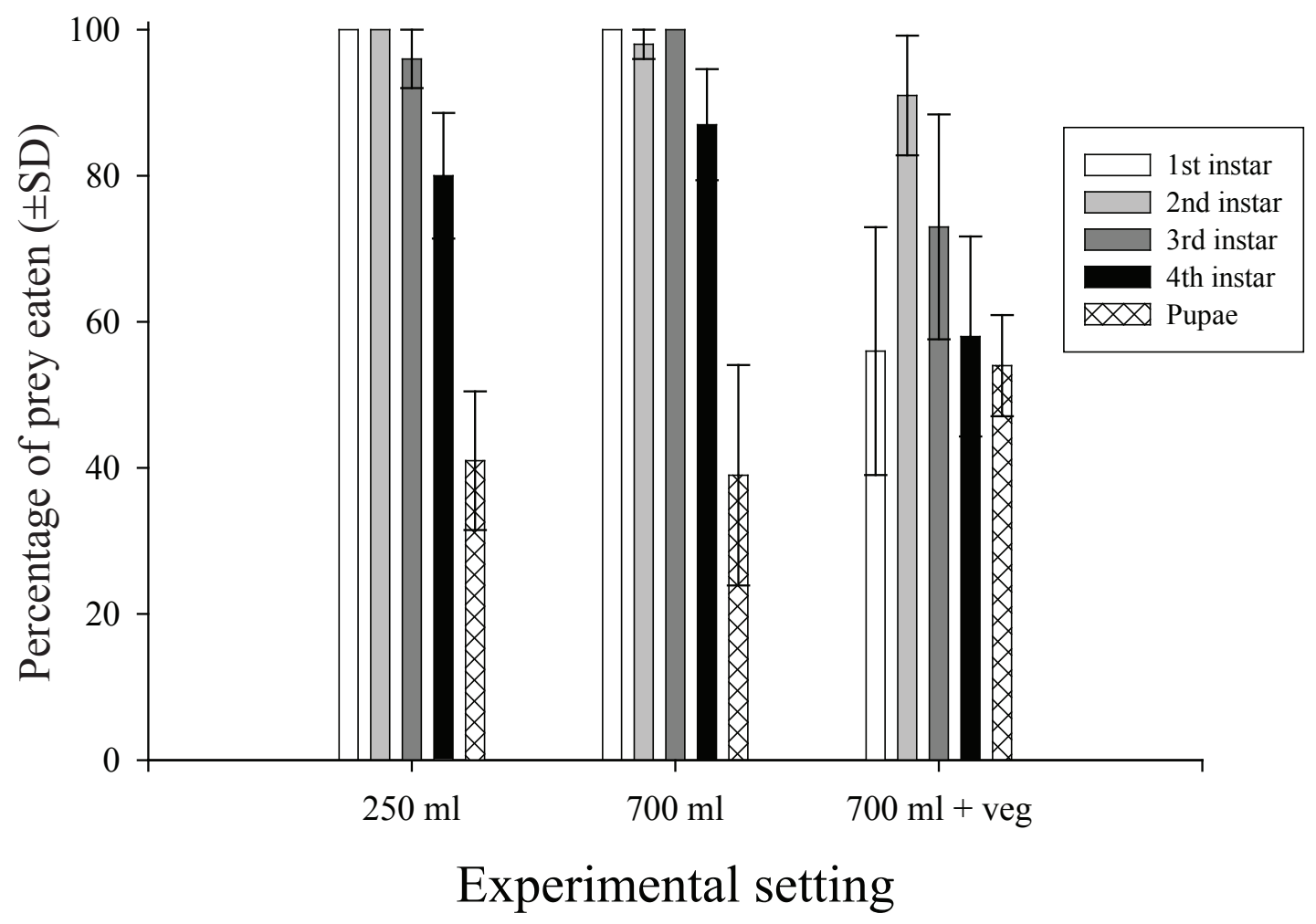

Figure 2. Predatorial capacity of Diplonychus sp. nymphs against different Culex annulirostris immatures in different settings (250 $\mathrm{ml}, 700 \mathrm{ml}$, and $700 \mathrm{ml}+$ vegetation). 
Table 3: Summary of predatorial efficacy on different prey stages by different predator groups in beakers. P-values refer to one-way ANOVA models over prey stages within each predator group.

\begin{tabular}{cccc}
$\begin{array}{c}\text { Prey } \\
\text { Stage }\end{array}$ & $\begin{array}{c}\text { Anisops sp. } \\
\text { adults (SD) } \\
\mathrm{p}<0.0001\end{array}$ & $\begin{array}{c}\text { Diplonychus } \\
\text { sp. } \\
\text { adults (SD) } \\
\mathrm{p}=0.44\end{array}$ & $\begin{array}{c}\text { Diplonychus } \\
\text { sp. } \\
\text { nymphs (SD) } \\
\mathrm{p}<0.0001\end{array}$ \\
\hline $1^{\text {st }}$ instar & $100(0)$ & $100(0)$ & $100(0)$ \\
$2^{\text {nd }}$ instar & $87(15.8)$ & $100(0)$ & $100(0)$ \\
$3^{\text {rd }}$ instar & $77(11.3)$ & $100(0)$ & $96(8.0)$ \\
$4^{\text {th }}$ instar & $54(18.3)$ & $100(0)$ & $80(8.6)$ \\
Pupa & $0(0)$ & $96.3(7.5)$ & $41(9.5)$ \\
\hline Total & $62.4(37.5)$ & $99.25(3.4)$ & $83.4(23.8)$ \\
\hline
\end{tabular}

insects that impacted the development and survival of $C x$. annulirostris immatures. These predators were dominated by Coleoptera (Dytiscidae and Hydrophilidae), Odonata ,and Hemiptera (Diplonychus sp., Plea sp. and Mesovlidae). Our predator survey revealed the presence of well-known predator species in Hemiptera and Odonata orders but did not find Coleoptera. During the monsoon period, both Diplonychus sp. and dragonflies prevailed, while only a limited number of Anisops sp. and damselflies were present. In a less tropical location in Southeast Queensland, Mottram and Kettle (1997) found a blend of coleopteran larvae, nymphs of Hemiptera (Anisops sp. and Diplonychus rusticus), and Odonata. These predators were significantly more common in flooded grassland than semi-permanent and temporary pools. In temperate Victoria, Australia, the commonest predators, from most prevalent to least, were beetle larvae, damsel fly naiads, and backswimmers (McDonald and Buchanan 1981). Insect predators may be more common in the wet tropics in which prey and habitat are available throughout the year.

In this study, predatorial capacity varied significantly with Diplonychus sp. emerging as superior. These results compare well to those obtained in southeast Queensland by Mottram and Kettle (1997). They tested seven predators in the laboratory and found that only D. rusticus and Coenagrionidae (Odonata) killed Cx. annulirostris pupae. Notonecta undulata, another common predator, was also found to avoid Ae. aegypti pupae (Ellis and Borden 1970).
All predators consumed a greater quantity of smaller instars than larger ones. This has been observed in the notonectids, N. undulata (Ellis and Borden 1970) and Enithares indica (Wattal et al. 1996), and Toxorhynchites splendens (Amalraj and Das 1998). The reason is thought to be that $1^{\text {st }}$ instars are easier to catch but provide less nutrition and must therefore be consumed in greater quantities than larger instars.

It was expected that an increase in forage area would decrease the attack rate of a predator which has to spend more time searching for the prey. However, the effect of an increased foraging area size, while significant overall, did not affect the predatorial capacity of adult Diplonychus sp. Diplonychus sp. adults are highly active predators that excel in alternating between stalking and fast attacks. Amalraj and Das (1998) also found that the attack rate of $T x$. splendens larvae against immature Ae. aegypti did not differ significantly among containers of different sizes. Similarly, capacity of the predaceous mosquito larvae Lutzia (= Culex) raptor was not influenced by difference in the volume of aquarium water ranging from 150 to $700 \mathrm{ml}$ (Prakash and Ponniah 1978). Thus, foraging area will affect predatorial capacity of some, but not all, predators.

The presence of vegetation significantly influenced predation activity in both nymph and adult Diplonychus sp. The influence was highly significant and more pronounced against $1^{\text {st }}, 3^{\text {rd }}$, and $4^{\text {th }}$ larval instar and pupal stage (adult stage only). This could be due to $C x$. annulirostris immatures having an affinity for vegetation in larval habitats. Likewise, $N$. maculata was generally most efficient at preying on the pelagic species Culiseta longiareolata than the vegetationdwelling Culex and Anopheles mosquitoes (Blaustein et al. 1995). Although this affinity is protective, it is not known if it is due to vegetation acting as a refuge or an anchoring point.

To summarize, surveyed predators were heavily reliant on seasonal rain and, in the arid tropics, were mostly found over the three-month long monsoon season. Diplonychus sp. was more efficient than Anisops sp. and also preyed well on pupae. This is important from a control point of view since pupal production is highly correlated with subsequent adult densities (Padgett and Focks 1981). Diplonychus sp. is thus recommended for further investigation as a potential biological control agent for mosquito immatures.

Table 4. Factorial ANOVA model for Diplonychus sp. adults and nymphs. 120 cases were processed with no missing cases.

\begin{tabular}{lcccc}
\multicolumn{1}{c}{ Source } & D.F. & Mean Squares & F Sig. & F Prob. \\
\hline Within+Residual & 108 & 210.54 & & $<0.001$ \\
Predator (Life Stage) & 1 & 3586.13 & 37.03 & $<0.001$ \\
Experimental Setting & 2 & 7015.06 & 33.32 & $<0.001$ \\
(forage area size and vegetation) & 4 & 5383.60 & 25.57 & $<0.01$ \\
Prey Life Stage & 4 & 832.9 & 3.96 & $<0.001$ \\
Predator * Prey Life Stage & 11 & 3862.03 & & \\
(Model) & 119 & 548.07 & & \\
(Total) & & & & \\
R-Squared $=0.651$ & & & \\
\hline
\end{tabular}




\section{REFERENCES CITED}

Amalraj, D.D. and P.K. Das. 1998. Estimation of predation by the larvae of Toxorhynchites splendens on the aquatic stages of Aedes aegypti. SE Asian J. Trop. Med. Pub. Hlth. 29: 177-183.

Blaustein, L, B.P. Kotler, and D. Ward. 1995. Direct and indirect effects of a predatory backswimmer (Notonecta maculata) on community structure of desert temporary pools. Ecol. Entomol. 20: 311-318.

Collins, F.H. and R.K. Washino. 1985. Insect predators. In: Chapman, H.C. (ed.) Biological control of mosquitoes. Bull. Am. Mosq. Contr. Assoc. 6: 25-42.

Ellis, R.A. and J.H. Borden. 1970. Predation by Notonecta undulata on larvae of the yellow fever mosquito. Ann. Entomol. Soc. Am. 63: 963-973.

Gooderham, J. and E. Tsyrlin. 2002. The Water Bug Book: A Guide to the Freshwater Macroinvertebrates of Temperate Australia. CSIRO, Canberra, Australia.

McDonald, G. and G.A. Buchanan. 1981. The mosquito and predatory insect fauna inhabiting fresh-water ponds, with particular reference to Culex annulirostris Skuse (Diptera: Culicidae). Aust. J. Ecol. 6: 21-27.

Miura, T. and R. Takahashi. 1988. Predation of Microvelia pulchella (Hemiptera: Veliidae) on mosquito larvae. J. Amer. Mosq. Contr. Assoc. 4: 91-93.
Mottram, P. and D.S. Kettle. 1997. Development and survival of immature Culex annulirostris mosquitoes in southeast Queensland. Med. Vet. Entomol. 11: 181186.

Padgett, P.D. and D.A. Focks. 1981. Prey stage preference of the predator, Toxorhynchites rutilus rutilus on Aedes aegypti. Mosq. News. 41: 67-70.

Prakash, R.N. and A.G. Ponniah. 1978. Predatory behaviour of Luzia on Culex fatigans. Hydrobiolgia 57: 159-162.

Rae, D.J. 1990. Survival and development of the immature stages of Culex annulirostris (Diptera: Culicidae) at the Ross river dam in tropical eastern Australia. J. Med. Entomol. 27: 756-762.

Scott, M.A. and W.W. Murdoch. 1983. Selective predation by the backswimmer, Notonecta. Limnol. Oceanography. 28: 352-366.

Venkatesan, P. and S. Sivaraman. 1984. Changes in the functional response of instars of Diplonychus indicus Venk. \& Rao (Hemiptera: Belostomatidae) in its predation of two species of mosquito larvae of varied size. Entomon 9: 191-196.

Washino, R.K. 1969. Progress in biological control of mosquitoes-invertebrate and vertebrate predators. Annual Conference of California Mosquito Control Association. 37: 16-19. (Cited in: Bay, E.C. 1974. Predatory-prey relationships among aquatic insects. 